\title{
Women autonomy and the use of antenatal and delivery services in Nigeria
}

\begin{abstract}
The ability of a woman to make independent decision and appropriate action on her reproductive desires is dependent on her level of autonomy. This study was undertaken to determine whether the level of autonomy of Nigerian women influences the use of antenatal and delivery services. A quantitative cross-sectional study using the Demographic and Health Survey (DHS) to determine whether an association exists between women's autonomy and the appropriate use of prenatal and delivery services. A total of 22,556 women aged 15-49 years were recruited using a stratified two stage proportionate to size cluster sampling from all parts of Nigeria. About $43 \%$ of respondents indicated that they do not independently take decision on health issues relating to their health, are not allowed to venture out of their matrimonial homes without seeking for permission and have no income and thus categorized as having no any form of autonomy. North East and South West zones had the lowest (18\%) and highest (62\%) proportion of women with full autonomy). Women with full autonomy are more likely to use prenatal (unadjusted odd ratio=2.229; CI 2.094-2.373) and delivery (Unadjusted Odd Ratio=3.795; CI 3.523-4.088)) services as recommended compared to women with no any form of autonomy (Adjusted Odd Ratio=1.129; CI 1.117- 1.146; $p<.05$ ). This study demonstrated that autonomy influences the use of Maternal Health Services (MHS) in Nigeria. There is the need for policy change on girl's education and women employment as well as dialogue with relevant Sociocultural structure like religious and traditional leaders in order to improve the level of autonomy and ultimately high use of MHS.
\end{abstract}

Keywords: autonomy, antenatal visit, place of delivery, Nigeria, socio cultural structure, ante natal care, ORC macro, ICF international, Calverton Maryland, enumeration
Volume 6 Issue 2 - 2017

\author{
Abubakar Sadiq Umar \\ School of Public Health,Walden University, USA
}

Correspondence: Abubakar Sadiq Umar, School of Public Health, College of Health Sciences, USA, Tel +263785467172 , Email abubakar.umar@waldenu.edu

Received: May 10, 2017 | Published:June 16, 2017
Abbreviations: DHS, demographic and health survey; MHS, maternal health services; ANC, ante natal care; WCBA, women of child bearing age; NDHS, Nigerian demographic and health survey; FCT, federal capital territory; LGAs, local government areas; EAs, enumeration areas; PSU, primary sampling unit; MCHCS, maternal and child health care services; IRB, institutional review board

\section{Introduction}

Autonomy is a combination of numerous subjects and domains that cuts across socioeconomic, political, local cultural norms, values, and beliefs system. Various published studies and reports have used different words to mean autonomy. For instance, empowerment, ${ }^{1-3}$ agency, ${ }^{1,4}$ independent decision making ${ }^{5}$ and volitional control ${ }^{6}$ were commonly used in different settings to mean autonomy. In relation to the use of maternal health services (MHS), female autonomy simply means the ability of a woman to make independent decision regarding her reproductive desires and where to seek for MHS such as prenatal, natal, post natal care including family planning services. Ultimately, it is the degree to which a woman makes an independent decision and takes action on reproductive issues even if it is in variation to her partner, in laws or other people in her family. ${ }^{3}$ The low proportion of women who made the recommended four ante natal care (ANC) visits before delivery was reported to be $<50 \%$ among countries in sub-Saharan Africa, Middle east, North Africa and the far east particularly Pakistan, Afghanistan and India compared to the nearly 90\% in Europe and Americas. ${ }^{7}$ Plausible reason advanced for the poor use of MHS in Africa and Middle east is women in these areas have no or limited autonomy, lack cultural liberation and generally dominated by men unlike their counterparts in western countries. ${ }^{89}$ The lack of capacity to take independent autonomous decision and action by women from these parts of the world might partially explain the poor utilization of MHS and poor pregnancy outcome in form of maternal and neonatal morbidity, mortality and disabilities. In sub Saharan Africa, less than half of all pregnant women between 2008-2012 had their first ANC visit in the first three months of being pregnant. ${ }^{7}$ This regional average does not highlight the wide variation within the African region. For example, only a mere $10 \%$ of pregnant women in Senegal commenced their ANC visit before the third trimester. ${ }^{10}$ Such behavior of late commencement of ANC will not facilitate the primary objective of ANC to identify high risk pregnancies and the institution of early management of these cases. ${ }^{11,12}$ In Nigeria, it has been reported that nearly two thirds of all pregnant women had made the first ANC visit towards the end of the second trimester. ${ }^{12}$ The late commencement of ANC could be one of the reasons why Nigeria has made the list of 11 countries where a woman is likely to die due to pregnancy and its complication. ${ }^{13}$ Furthermore, lack of autonomy may result in late decision making, delay to reach the nearest maternity hospital and getting the appropriate management which aptly explains the 3 Delays (3D) Model. ${ }^{14}$ Literature review indicated that Sociologist and population scientist seem to use several variables in order to measure the autonomy of women depending on the objective of a study. Variables like education, income, employment, age at first sexual intercourse, age of her spouse or partner, having fixed assets (land, house, farm), owning gold, pearls or silver, living in the 
same compound with mother in-law, who decides what to be eaten, which school her children will attend, how family income should be spent and whether she needs permission before venturing out of her matrimonial home., ${ }^{4,5,15,16}$ These variables could be seen in the context of social influencers of population health outcomes as they cut across women place of birth, their place of work and living which by extension defines opportunities and cultural stereotyping within a specific place and time.

It is important to state that not all of these variables used by the social and demographic scientist are available in the Demographic and Health Survey (the source of data for this study). In order to measure female autonomy in the context of MHS, we have used three variables namely: a) income independence (having a paying job); b) participation in family level decision making process on health issues; and c) freedom to go out of her matrimonial home on health issues without the need to ask for permission from anybody. The influence of these variables on the use of MHS were well documented, however, research in countries with similar challenges on women empowerment and equality was reported to be unequivocal. ${ }^{8,9,17,18}$ These studies suggested the need for more community based studies in order to provide better insights on the influence of these variables on MHS. This study is therefore an attempt to provide local findings within the Nigerian state using secondary analysis of the raw data of the demographic and health survey that has a sample size of 22,556 and participants drawn from all the states and the Federal Capital Territory using a 2 stage clustered and proportionate to size sampling methods as described in details in the methodology section. The research question was whether Nigerian women's characteristics as measured by their level of autonomy is associated with use of MHS in terms of the number of ante-natal visits and place of delivery? The objectives of the study are to:

a. To determine the level of female autonomy among the various geopolitical zones of Nigeria.

b. To determine whether the level of female autonomy influences the use of MHS.

\section{Methodology}

Nigeria lies in the West African sub region and has an estimated total population of 143 million, out of which about 32 million are women of child bearing age (WCBA). The annual estimated number of pregnancies is 8.3 million. The country is divided into 36 states plus a federal capital territory. The 36 states were clustered into six geopolitical zones based on historical and socio cultural similarities (Figure 1). Health is a concurrent responsibility of all tiers of Government namely federal, state and local governments.

Quantitative cross-sectional study using secondary data of the Nigerian Demographic and health Survey (NDHS). Permission to use the NDHS data was granted by ORC Macro and ICF International, Calverton Maryland, USA. The data was used to determine whether an association exists between the level of autonomy of Nigerian women and the use of MHS in terms of the number of ante-natal visits and place of delivery? Women that have responded yes to having an independent income, participate in family level decision making process on health issues and has freedom to go out of her matrimonial home on health issues without the need to ask for permission from anybody were coded as 1 (full autonomy), those that respondent yes to only one or two of these variables were coded 2 (some autonomy) and those that response no to all the three measures of autonomy were coded 0 (no autonomy). Comparison was made between women who had no any form of autonomy with those with some or full autonomy. The number of ANC visits was categorized as less than 4 or $\geq 4$ and place of delivery was grouped as home or health facility.

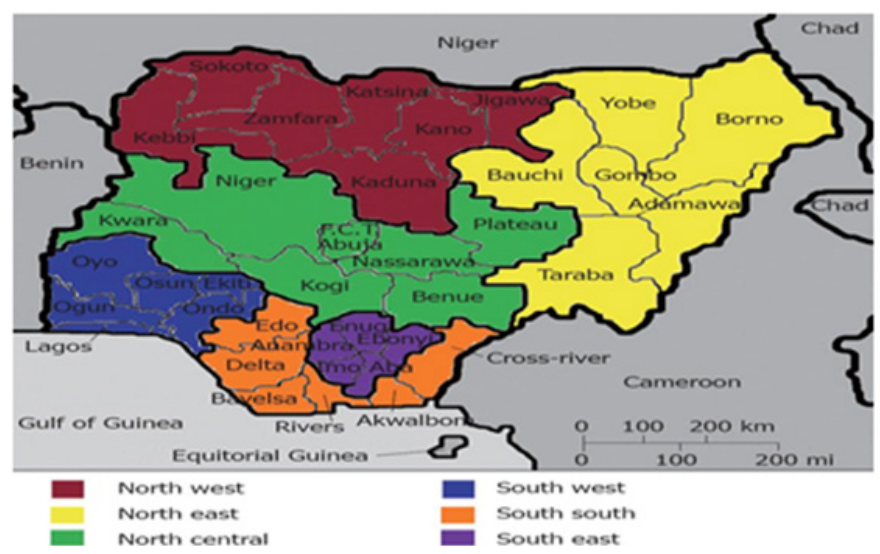

Figure I Map of Nigeria showing states and geopolitical zones.

The Federal republic of Nigeria is organizationally divided into 36 states and a Federal Capital territory (FCT). Each of the state and the FCT is further subdivided into districts called local government areas (LGAs), and each LGA is divided into political wards. During national census, each of the political wards is further subdivided in to enumeration areas (EAs). The first level of cluster selected during the survey was the random selection of EAs from the list of each EAs (sampling frame) in each state and the FCT which then forms the primary sampling unit (PSU) for the survey data that I have used for this study. ${ }^{20} \mathrm{~A}$ total of 888 clusters (286 are urban and 602 are rural areas) were selected, in each cluster households were selected based on the weighted population size. The mapping and line listing of households in each of the EAs was conducted and was the sampling frame for the second stage of the cluster sampling strategy used..$^{20}$ Within each selected household, a woman was randomly selected from the list of all women who had given birth within a year before the survey date. Additional details of the sample size estimation and sampling techniques is available online. ${ }^{20}$ The survey was jointly sponsored by United States of America International Development, The Nigerian Nation Population Commission and other international partners. ${ }^{20}$

A total of 22,556 women aged 15-49years were analyzed based on the composite 3 variables of autonomy mentioned above. The large sample has underscored the external validity of this study ${ }^{19}$ and also because of the two stages clustered sampling proportionate to the population size of each cluster. ${ }^{20}$ Data was analyzed using SPSS. Based on the research questions and study objectives earlier mentioned above, the research hypotheses are:

Ho1: There is no significant statistical association between the level of autonomy of Nigerian women and the use of MHS as measured by the number of antenatal visits and place of delivery.

Ho2: There is a significant statistical association between the level of autonomy of Nigerian women and the use of MHS as measured by the number of antenatal visits and place of delivery.

The dependent/outcome variables are dichotomous categorical with antenatal clinic visits $(<4$ or $\geq 4)$ in line with recommendation of 
the World Health Organization, ${ }^{13}$ while place of delivery categorized as home or institutional). Bivariate Pearson Chi-square statistic and Multivariate logistic regression were used to analyze associations and develop models. Possible confounders were controlled based on finding from other studies and likely theoretical influencers. A similar analytical approach using previous Nigerian demographic and health survey data was used to determine the magnitude and factors influencing Maternal and Child Health care Services (MCHCS). ${ }^{21,22}$

\section{Ethical issues}

This study was approved by the Institutional Review Board (IRB) of Walden University, Minneapolis, USA with an IRB approval number 01-23-15-0338613 dated 24 ${ }^{\text {th }}$ January, 2015.

\section{Results}

Out of the 22,556 respondent, $43.1 \%$ and $38.2 \%$ were found to have no any form of autonomy and full autonomy respectively. Women from the North East and South West zones had the lowest $(18 \%)$ and highest $(62 \%)$ proportion of women who reported to have full autonomy (Table 1).

Table I Category of autonomy by geopolitical zone of residence

\begin{tabular}{llll}
\hline \multirow{2}{*}{ Geopolitical zone } & \multicolumn{3}{l}{ Proportionate category of autonomy* } \\
\cline { 2 - 4 } & None & Some & Full \\
\hline North east & 63.8 & 18.2 & 18.0 \\
North west & 63.3 & 16.8 & 19.8 \\
North central & 45.2 & 20.6 & 34.2 \\
South east & 22.6 & 19.8 & 57.6 \\
South south & 28.6 & 18.7 & 52.7 \\
South west & 19.0 & 19.0 & 62.0 \\
Nigeria (Total) & 43.1 & 18.7 & 38.2 \\
\hline
\end{tabular}

*All values are in percentage, Only $25.3 \%$ and $43 \%$ of women with no any form of autonomy and those with full autonomy respectively had made the minimum desired 4 ANC visits in their last pregnancy before the survey (Figure 2).

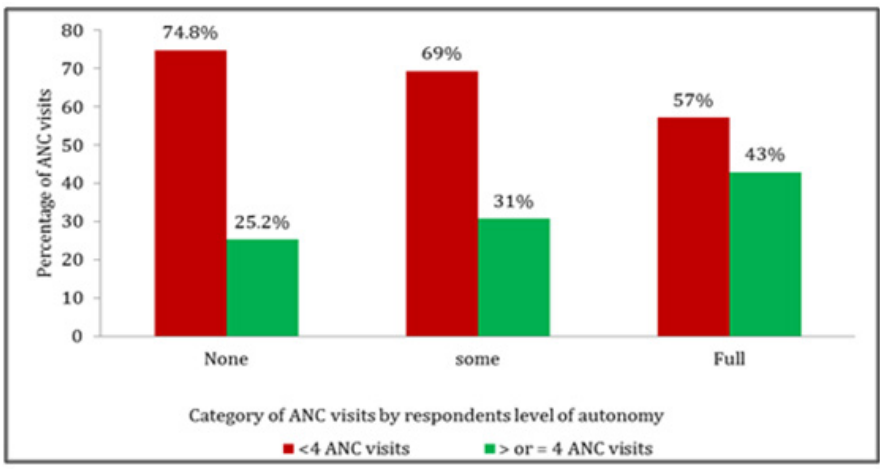

Figure 2 Women autonomy and antenatal visits.

There is a significant statistical association between women's autonomy and the number of ANC visits $(\chi 2=659.642 ; \mathrm{df}=2 ; p<.001)$ (Table 2). Those with full autonomy have two fold likelihood to attain the minimum four ANC visits compared to women with no any form of autonomy (UOR=2.229; CI $2.094-2.373$ ). However, after controlling covariates such as educational attainment, personal income, geographical zone, place of residence (rural/urban), religious beliefs and ethnicity, there was no significant statistical difference between the category of autonomy a woman belongs to and the number of ANC visits (AOR=1.000; CI $0.742-1.348 ; p>.05$ ) (Table 2).

The level of autonomy has significant statistical association with place of delivery $(\chi 2=1321.02 ; \mathrm{df}=2 ; p<001)$. Women who are fully autonomous have four folds likelihood to deliver in a health facility compared to those with no autonomy (UOR $=3.795$; CI 3.523-4.088) (Table 3). This pattern was consistent following the control of covariates and $(\mathrm{AOR}=1.129$; $\mathrm{CI} 1.117-1.146 ; p<.05)$ (Table 3$)$.

Table 2 Association between the levels of women's autonomy and the number of antenatal visits *p is significant at the 0.05 level

\begin{tabular}{|c|c|c|c|c|c|c|c|c|c|c|}
\hline \multirow{3}{*}{\multicolumn{2}{|c|}{ Level of autonomy }} & \multirow{3}{*}{$\begin{array}{l}\geq 4 \\
\text { Visits }\end{array}$} & \multirow{3}{*}{$\begin{array}{l}\text { Bivariate } \\
\text { analysis } \\
\text { Pearson's chi- } \\
\text { square }\end{array}$} & \multicolumn{7}{|c|}{ Multivariate logistic regression analysis } \\
\hline & & & & \multirow[t]{2}{*}{ UOR } & \multicolumn{2}{|c|}{ 95\% CI For AOR } & \multirow{2}{*}{$\begin{array}{l}\text { AOR } \\
\text { imit }\end{array}$} & \multirow[t]{2}{*}{$\begin{array}{l}\mathbf{P} \\
\text { Values }\end{array}$} & \multicolumn{2}{|c|}{ 95\% CI For AOR } \\
\hline & & & & & \multirow[t]{2}{*}{$\begin{array}{l}\text { Lower } \\
\text { Limit }\end{array}$} & Upper Limit & & & $\begin{array}{l}\text { Lower } \\
\text { Limit }\end{array}$ & $\begin{array}{l}\text { Upper } \\
\text { Limit }\end{array}$ \\
\hline None & 7271 & 2453 & & I & & & 1 & & & \\
\hline Some & 2921 & 1293 & $0.00 I^{*}$ & 1.312 & 1.211 & 1.421 & 1.146 & 0.069 & 0.826 & 1.59 \\
\hline Full & 4919 & 3699 & & 2.229 & 2.094 & 2.373 & I & 0.923 & 0.742 & 1.348 \\
\hline
\end{tabular}

Variables adjusted in the model: education, family income, ethnicity, religion, geopolitical zone of residence, and place of domicile

Table 3 Association between the levels of women's autonomy and the place of delivery

Place of delivery $\mathrm{Bi}$ variate analysis multivariate logistic regression analysis

\begin{tabular}{|c|c|c|c|c|c|c|c|c|}
\hline \multirow[t]{2}{*}{ Home } & \multirow[t]{2}{*}{ facility } & \multirow[t]{2}{*}{$\begin{array}{l}\text { Pearson's chi- } \\
\text { square }\end{array}$} & \multirow[t]{2}{*}{ UOR } & \multicolumn{2}{|c|}{ 95\% Cl for UOR } & \multirow[t]{2}{*}{ AOR P value } & \multicolumn{2}{|c|}{ 95\% CI for AOR } \\
\hline & & & & Lower limit U & Upper limit & & Lowe & Upper limit \\
\hline 5863 & 1565 & & I & & & I & & \\
\hline 2166 & 968 & $0.001 *$ & 1.674 & $\mathrm{I} .524$ & 1.839 & 0.4570 .063 & 0.394 & 0.578 \\
\hline 3143 & 3184 & & 3.795 & 3.523 & 4.088 & I.I29 0.00I* & 1.117 & I. 146 \\
\hline
\end{tabular}

$*_{\mathrm{p}}$ is significant at the 0.05 level

Note Variables adjusted in the model: education, family income, ethnicity, religion, geopolitical zone of residence, and place of domicile 


\section{Discussion}

In this study, women's autonomy was measured as economic independence, autonomous decision making capacity and freedom of movement in order to assess their influence on the use of MHS. Lowest levels of autonomy was found among women living the North Eastern and North Western regions of Nigeria compared to any of the three zones in Southern and North central Nigeria. These zones (North East and North West) have nearly two thirds of all of women with no any form of autonomy in terms of participation in decision making process on reproductive health issues, having personal income and venturing out their matrimonial homes without seeking permission from their husband or relative of the husband. The lack of autonomy in these zones was partially accountable for the lowest use of MHS even after controlling for the differences in the level of education, family income, ethnicity, religion, geopolitical zone of residence, and place of domicile (rural or urban). This finding is consistent with a previous report that women from the southern and North Central parts of the country having between two to nine folds more likelihood to use MHS compared to the North East and North West zones. ${ }^{23}$ Furthermore, the zones with the lowest level of autonomy and use of MHS were areas where the proportion of female literacy level and gainful employment is low with nearly a fifth of all women as illiterates and unemployed (more likelihood to use MHS compared to the North East and North West zones. ${ }^{20,23}$ Plausible reasons for the low level of autonomy accorded to women and concomitant low use of MHS in the North West and North East geopolitical zones of Nigeria could be religious beliefs and cultural values. These zones are predominantly belonging to Hausa, Fulani and Kanuri ethnic groups and adherents of the Islam faith constituting well over half the population in these zones. Ethnicity and religious beliefs were reported to have negative influence on the use MHS particularly where there is a lack of female health workers and large gap in knowledge on the benefits of modern obstetric care. ${ }^{18,24}$ The impact of cultural beliefs on the use of MHS is exemplified by a study in some parts of North Western Nigeria, where it was reported the lithotomy position is embarrassing and demeaning particularly in the presence of non-family members such as health workers. ${ }^{25}$ This further strengthen the need for systematic proactive community engagement when planning the provision of a given health service in order to take in to considerations the concerns of the local communities. While in this study the use of MHS was found to be significantly associated with the level of autonomy, however, this finding is contrary to studies in Kenya, ${ }^{8} \mathrm{Nepal}^{26}$ and Pakistan $^{9,27}$ reported that the use of MHS is similar among women irrespective of their level of freedom of movement, empowerment, and participatory decision making process at the family level. The Kenyan study advanced that cost of services rendered and transport were the underlying root causes for lower use of MHS. ${ }^{8,17}$ Similarly, the Pakistani study underscored that generally women have freedom to go out of their matrimonial homes as part of social obligation within the family and neighbourhood structure and therefore not a valid measure for autonomy. ${ }^{9,27}$ However, this assertion is invariance with a study in rural parts of Kano state Nigeria, where women are kept in seclusion and go out of their matrimonial homes after getting permission from her spouse or other elderly family member irrespective of the need for her to go out. ${ }^{28}$ Overall this indicates the freedom of movement by married women as a variable to assess her level of autonomy showed variation among cultures of different parts of the world. Several studies have been reported on the poor use of MHS in East $^{18,29}$ and West ${ }^{28,30-34}$ African countries had indirectly suggested significant proportion of women are fully dependent on their husband and family in order to pay for services rendered in health facilities. By extension the authors in our opinion have indicated that, these women lack financial independence, incapable to decide on where and when to go and to get medical services as they are dependent on financial and mind set of whoever is going to pay their health bills. It is important to note that, in the context of North Eastern and Western Nigeria, reports indicated that Purdah (seclusion of women) is widely practiced particularly in the North West ${ }^{20}$ which curtails the movement of women even on health grounds. This inconsistent find requires a mixed research method of both qualitative and quantitative methods in order to compliment insights on the cultural norms, values and tradition with respect to autonomy of women and the use of health services.

\section{Conclusion and recommendation}

The findings of my study indicated that: a) the majority of women living in the Northern parts of Nigeria have the highest proportion of women who have no any form of autonomy which is not only higher than the national average but also twice that of the southern zones; b) the lower the level of autonomy, the less likelihood a woman will make the four recommended number of antenatal clinic visit and or deliver in a health facility suggesting the use of MHS will be lowest in the Northern parts of the country compared to the southern zones; and c) the level of autonomy of Nigerian women is strongly associated with the use of antenatal and delivery service even after controlling for confounders such as education, family income, ethnicity, religion, geopolitical zone of residence, and place of domicile. In order to reverse the appalling scenario observed in all the 3 northern geopolitical zones, there is the need for community sensitization and education by engaging local community leaders on the benefits of empowering women to improve their level of autonomy.

\section{Strengths and weaknesses of this study}

This study analyzed data of over 22,000 women that were randomly selected from all states and the Federal Capital Territory; which increases the external validity and generalizability of the results and conclusions. ${ }^{12}$ Findings established the influence of female autonomy on the use of MHS after adjusting for covariates such as education, income, ethnicity, religion, geopolitical zone of residence, and place of domicile. However, this does not mean causality and only demonstrated significant statistical association between the use of MHS and level of female autonomy. Additionally, because the DHS data is basically quantitative, information on the process of making health related decisions and negotiations within family structure are missing which could have provided additional insights on female autonomy and how it impact the use of MHS. This points the need for additional qualitative research in order to have a holistic view of autonomy and the use of MHS.

\section{Acknowledgements}

None.

\section{Conflict of interest}

Author declares that there is no conflict of interest.

\section{References}

1. Ahmed S, Creanga AA, Gillespie DG, et al. Economic status, education and empowerment: Implication for maternal health services utilization in Developing countries. PLoS One. 2010;5(6):e1190.

2. Ibrahim S, Alkire S. Agency and power: A proposal for internationally comparable indicators-OPHI working paper. OPHI Working Paper series. University of Oxford. Oxford, United Kingdom; 2007. 
3. Mason KO, Smith HL. Women's empowerment and social context: Results from five Asian countries. Rockefeller's Foundation Bellagio study and conference center. Via Giuseppe, Bellagio, Italy; 2003.

4. Mason KO. The status of women: Conceptual and methodological issues in demographic studies. Sociological Forum. 1986;1(2):284-300.

5. Amowitz LL, Reis C, Lacopino V. Maternal mortality in Herat Province, Afghanistan, in 2002: An indicator of women's human rights. JAMA 2002;288(10):1284-1291.

6. Burchardt T, Evans M, Holder H. Measuring inequality: Autonomy the degree of empowerment in decisions about one's own life. Centre for Analysis of Social Exclusion. Oxford University, Oxford, United Kingdom; 2010.

7. Population health indicators. World Health Statistics 2013. Geneva: World Health Organization (WHO); 2013.

8. Fatso JC, Ezeh AC, Essendi H. Maternal Health in poor Resource urban settings: How does women's autonomy influence the utilization of obstetric care services? Reproductive Health. 2009;6:9.

9. Mumtaz Z, Salway S. Understanding gendered influences on women's reproductive health in Pakistan: Moving beyond the autonomy paradigm. Soc Sci Med. 2009;68(7):1349-1356.

10. Population health indicators. World Health Statistics 2014. Geneva: World Health Organization (WHO); 2014.

11. Ezugwu EC, Agu PU, Nwoke MO, et al. Reducing maternal deaths in poor resource setting in Nigeria. Niger J Clin Pract. 2014;17(1):62-66.

12. Wang W, Alva S, Wang S, et al. Levels and trends in the utilization of maternal health services in developing countries. Calverton, Maryland: ICF Macro; 2011.

13. Trends in Maternal Mortality: 1990 to 2008 Estimates. World Health Organization. United Nations Children's Fund. United Nations Population Fund. The World Bank. Geneva: World Health Organization (WHO); 2010

14. Thaddeus S, Maine D. Too far to walk: maternal mortality in context. Soc Sci Med. 1994;38:1091-1110.

15. Bloom SS, Wypij D, Das Gupta M. Dimensions of women's autonomy and the influence on maternal health care utilization in a north Indian city. Demography. 2001;38(1):67-78.

16. Cook RJ, Dickens BM. Human rights to safe motherhood. Int J Gynaecol Obstet. 2002;76(2):225-231.

17. Fatso JC, Ezeh AC, Oronje R. Provision and use of maternal health services among urban poor in Kenya: What do we know and what can we do? J Urban Health. 2008;85(3):428-442.

18. Magoma M, Requejo J, Campbell OMR, et al. High ANC coverage and low skilled attendance in a rural Tanzanian district: A case for implementation of birth plan intervention. Gender, class and exclusion. BMC Pregnancy Childbirth. 2010;10:13.
19. Szklo M, Nieto FJ. Understanding a Lack of Validity: Bias in Epidemiology: Beyond the basics. 3rd ed. Sudbury, MA: Jones and Bartlett; 2014

20. Nigeria Demographic and Health Survey. National Population Commission and ICF Macro. Abuja, Nigeria, MD USA; 2009.

21. Antai D. Faith and child survival: the role of religion in childhood immunization in Nigeria. J Biosoc Sci. 2009;41(1):57-76.

22. Fapohunda B, Orobaron N. Factors influencing the selection of delivery with no one present in Northern Nigeria: implications for policy and programs. Int J Womens Health. 2014;6:171-183.

23. Primary Health Care in Nigeria: 30years after Alma-Ata. The Nigerian Health Review. Health Reform Foundation of Nigeria. Abuja, Nigeria: Mmm-nat Educational Window Consultant Ltd; 2007.

24. Fawole AO, Shah A, Fabanwo AO, et al. Predictors of maternal mortality in institutional deliveries in Nigeria. Afr Health Sci. 2012;12(1):32-40.

25. Ityavyar DA. A traditional midwife practice in Sokoto state, Nigeria. Soc Sci Med. 1984;18(6):497-501.

26. Furuta M, Salway S. Women's position within the household as a determinant of maternal health care use in Nepal. Int Fam Plan Perspect. 2006;32(1):17-27.

27. Mumtaz Z, Salway S, Shanner L, et al. Addressing disparities in maternal health care in Pakistan: Gender, class and exclusion. BMC Pregnancy Childbirth. 2012;12:80

28. Adamu YM, Salihu HM. Barriers to the use of antenatal and obstetric care services in rural Kano, Nigeria. J Obstet Gynaecol. 2002;22(6):600-603.

29. Montagu D, Yamey G, Visconti A, et al. Where do poor women in developing countries give birth? A multi-country analysis of demographic \& health survey data. PLOS ONE. 2011;6(2):1-8.

30. Idris SH, Gwarzo UMD, Shebu AU. Determinants of place of delivery among women in semi urban settlement in Zaria, Northern Nigeria. Annals of African Medicine. 2006;5(2):68-72.

31. Babalola S, Fatusi A Determinants of use of maternal health services in Nigeria - looking beyond individual and household factors. $B M C$ Pregnancy Childbirth. 2009;9:43.

32. Olarenwaju FO. Women empowerment as a determinant for investment in children in selected rural communities in Nigeria. African Research Review. 2013;7(4):138-161.

33. Oche M, Umar AS, Adejoh MA, et al. Determinants of utilization of maternity services in Gidan Igwe, Sokoto, Nigeria. Sahel Medical Journal. 2010;13(3):128-134.

34. Umar I, Oche M, Umar AS. Patient waiting time in a tertiary health institution in Northern Nigeria. Journal of Public health and Epidemiology. 2011;3(2):78-82. 